УДК 811.134.2

DOI 10.23951/1609-624X-2020-2-61-67

\title{
ЛИНГВОПРАГМАТИЧЕСКИЙ АСПЕКТ РОЖДЕСТВЕНСКИХ ОБРАЩЕНИЙ ФИЛИППА VІ
}

\section{И. В. Селиванова}

\author{
Московский государственный университет им. М. В. Ломоносова, Москва
}

\begin{abstract}
Введение. Изучены стратегии и тактики речевой манипуляции в рождественских обращениях испанского монарха Филиппа VI с 2014 по 2019 гг.

Материал и методы. Исследование проведено на материале шести рождественских посланий Филиппа VI, опубликованных на официальном сайте Королевского дома Испании. В работе применяются как общенаучные методы (описание, наблюдение, обобщение и систематизация), так и методы лингвистического анализа (лингвоидеологическая интерпретация, контент-анализ, дискурсивный анализ).

Результаты и обсуждение. Рождественская речь анализируется в контексте политической риторики как нацеленный на публичное воздействие акт представительской коммуникации. Описываются конститутивные характеристики и коммуникативные детерминативы рождественских посланий Филиппа VI с 2014 по 2019 г. с учетом современного политического контекста Испании. Особое внимание уделяется используемым стратегиям и тактикам речевой манипуляции, обеспечивающим акт торжественного красноречия, а также центральным образам прошлого и настоящего, адресанта и адресата (общества), определяющим концептуальное пространство рождественского обращения. Научная новизна работы заключается не только в анализе коммуникативного и образного потенциала посланий монарха, но и в описании характерных признаков данного вида публичного выступления.

Заключение. Рождественское обращение монарха представляет собой типичный пример направленного на воспитание определенных качеств торжественного красноречия. При этом глава государства выступает значимой общественной фигурой, обладающей правом не только толковать факты и события действительности (с целью сохранения единства нации и стабильности государства), но и обсуждать нравственные проблемы, основываясь на общечеловеческих ценностях как духовных скрепах социума. Рождественские послания Филиппа VI полностью соответствуют требованиям торжественного публичного выступления как особого коммуникативного события и характеризуются традиционным набором образов (адресата и адресанта), транслируемых ценностей (демократических и общечеловеческих) и стратегий речевого воздействия (стратегия самопрезентации, информационно-интерпретационная стратегия, аргументативная стратегия, агитационная стратегия, стратегия формирования эмоционального настроя адресата), подчеркивающих роль монарха как единственного хранителя и гаранта коллективной идентичности, процветания и стабильности государства.
\end{abstract}

Ключевые слова: рождественское обращение, испанский монарх, Филипп VI, ритуальный жанр, политический дискурс.

\section{Введение}

В процессе коммуникации язык используется не только для передачи информации, но и с целью воздействия на реципиента. С его помощью представляется возможным регулировать межличностные и социальные отношения, эмоции и поведение людей. В настоящее время наблюдается особый интерес к исследованию феномена речевой манипуляции. О. Н. Быкова описывает ее как «вид языкового воздействия, используемый для скрытого внедрения в психику адресата целей, намерений, отношений или установок, не совпадающих с теми, которые имеются у адресата в данный момент»; Е. В. Денисюк рассматривает речевую манипуляцию как «специфическое речевое поведение в процессе общения, направленное на побуждение собеседника совершить невыгодное для него (но выгодное для побуждающего лица) действие»; Л. А. Нефедова - как «скрытое или неявно выраженное воздействие посредством языка на мнение и поведение адресата», как попытку «склонить адресата к своей точке зрения», как «стремление извлечь выгоду для себя, маскируя при этом свои подлинные намерения»; Г. А. Копнина - как «разновидность манипулятивного воздействия, осуществляемого путем искусного использования определенных ресурсов языка с целью скрытого влияния на когнитивную и психологическую деятельность» [1, с. 24-25]. Нетрудно заметить, что приведенные определения имеют схожие черты: в указанных цитатах речь идет о психологическом воздействии скрытого для адресата характера.

Политическая манипуляция (манипулирование) представляет собой систему скрытого управления политическим сознанием и поведением масс с целью принудить их действовать или бездействовать в интересах манипуляторов. Иными словами, речь идет о навязывании адресату выгодных для адресанта установок, целей и желаний, что позволяет считать ее средством социального принуждения. К ней прибегают с целью подавления социальной активности населения, представляющей 
непосредственную угрозу господствующему социальному классу, и направления ее в нужное русло [2, с. 148-149].

В лингвистической литературе ведутся активные споры по поводу различий между речевой манипуляцией и речевым воздействием (И. А. Стернин, А. А. Данилова, Г. А. Копнина, К. Ф. Седов, О. С. Иссерс и др.). Например, И. А. Стернин считает, что главным критерием, разграничивающим эти понятия, выступает сознательность или бессознательность действий адресата: «Речевое воздействие - это воздействие на человека при помощи речи с целью убедить его сознательно принять нашу точку зрения, сознательно принять решение о каком-либо действии, передаче информации и т. д. А манипулирование - это воздействие на человека с целью побудить его сообщить информацию, совершить поступок, изменить свое поведение и т. д. неосознанно или вопреки его собственному мнению, намерению» [3]. Однако на практике часто эти понятия взаимозаменяемы.

Главная цель политических лидеров - получение и удержание власти - достигается с помощью использования разнообразных стратегий речевой манипуляции (речевого воздействия): от преднамеренного искажения фактов посредством закрепления за ключевыми словами не свойственных им ранее коннотаций до использования разнообразных средств языковой выразительности (стилистических фигур и тропов) [4, с. 174]. При этом тенденция к использованию возможностей перестройки сознания является характерным признаком любого современного (даже демократического) общества. Манипуляция сознанием через различные каналы коммуникации является наиболее простым и эффективным способом укрепления своих позиций. Именно поэтому речь главы государства представляет собой продуманный с точки зрения ораторского мастерства фрагмент текста, способный повлиять на ценностные установки аудитории и ее восприятие действительности.

В рамках настоящей статьи рассматриваются стратегии и тактики речевой манипуляции в испанском политическом дискурсе на примере рождественских речей Филиппа VI с 2014 по 2019 гг. в лингвопрагматическом аспекте.

\section{Результаты и обсуждение}

Речевая манипуляция в политическом дискурсе представляет собой одну из наиболее серьезных и широко освещаемых проблем в современных гуманитарных науках. Причины интереса к этому феномену необходимо искать в общем ходе мирового развития в XX - начале XXI в., особенностях общественных и социально-экономических преобразований, изменении всего образа жизни общества и нарастании глобальной неустойчивости и противоречий, которые привели к катастрофическим по своим последствиям войнам [2, с. 148].

Анализ научной литературы по рассматриваемой тематике позволил отметить ряд лингвопрагматических характеристик речевой манипуляции в политической коммуникации: а) скрытый характер функции воздействия обусловливает не только построение текста, но и использование языковых средств и речевых приемов воздействия (адресант скрывает подлинную цель своего сообщения); б) конечная цель сообщения заключается в изменении системы ценностных ориентиров и идеологических установок аудитории; в) субъект политической коммуникации контролирует эффективность манипуляции, организуя смысловое содержание своего выступления, подбирая соответствующие речевые способы, вербализирующие манипулятивные методы и приемы воздействия на сознание объекта; г) объектом психического воздействия манипулятора может быть как индивидуальное, так и коллективное сознание (во втором случае речь идет об управлении общественным мнением с целью изменения поведения национальной языковой общности или конкретной социальной группы); д) основным средством осуществления целенаправленного скрытого воздействия на подсознание и сознание объекта манипуляции является текст, реализуемый в устной или письменной форме [5].

В практике политической коммуникации речевое воздействие осуществляется с помощью конкретных приемов, выбор которых зависит от преследуемых адресантом целей и задач [6]. В научных исследованиях, посвященных изучению особенностей политического дискурса, представлены попытки классификации манипулятивных стратегий и тактик [7]. В рамках настоящего исследования используется классификация О. Н. Паршиной, к которой наиболее часто прибегают при описании речевого воздействия в различных жанрах политического дискурса [8].

\section{Рождественская речь испанского монарха: общие замечания}

Выступление испанского монарха накануне Рождества считается традиционным актом политической коммуникации, во время которого первое лицо обращается с поздравлением ко всему народу, подводит итоги уходящего года, определяет основные векторы дальнейшего развития страны и делает прогнозы на будущее [9-17]. Это послание представляет собой общение в рамках заданных статусно-ролевых отношений и относится прежде всего ритуальному (эпидейктическому) жанру институционального дискурса, направленному на сохранение существующего политического режима 
[18]. Эта коммуникативная практика имеет формальную фиксацию, символическую нагруженность и характеризуется цикличностью, а также тематической, лингвопрагматической и стилистической спецификой. Занимаемая монархом позиция задает тематику сообщения: его содержание всегда касается внутриполитических и международных проблем и отличается нейтральным тоном изложения информации. Выступление монарха представляет собой типичный пример направленного на воспитание определенных качеств торжественного красноречия, помещенного в проблемный политический и экономический контекст. При этом глава государства выступает в роли значимой общественной фигуры, имеющей право не только толковать факты и события действительности, но и обсуждать нравственные проблемы, основываясь на общечеловеческих ценностях как духовных скрепах социума (с целью сохранения единства нации и стабильного развития государства).

Главное событие, к которому приурочено обращение, является конфессиональным праздником, отмечаемым всеми христианами мира, а наступающий Новый год - важным поводом для обращения к нации (независимо от вероисповедания подданных) для подведения итогов уходящего года и определения векторов развития на будущее. С точки зрения структуры рождественская речь содержит обращение к адресату, конгратуляционную часть (поздравление), констатирующую часть и оптатив (пожелания). Участниками данного события выступает король Испании (Филипп VI) и самая широкая зрительская аудитория (жители Испании). Адресатом рождественского обращения является страна и каждый индивид в отдельности, не имеющий эксплицитного выражения. В силу своего социального статуса категория адресанта в рассматриваемом жанре является ключевой, поскольку во многом определяет форму и содержание текста.

Рождественские послания Филиппа VI (c 2014 по 2019 г.) выстроены по классическому типу и значительно не отличаются по своей структуре и содержанию. Монарх в начале своего выступления отмечает важность момента, который дает возможность сблизиться, и благодарит своих подданных за уделенное внимание:

[...] os agradezco que me permitáis nuevamente compartir con vosotros unos minutos en esta noche tan especial... (2019).

Эмоциональная подача материала является характерной чертой выступлений Филиппа VI, который активно использует средства невербальной коммуникации (жестикуляция, нахмуривание бровей, открытая поза и отсутствие визуальных барьеров) с целью подчеркнуть значимость обсуждаемых вопросов и свою вовлеченность в происходя- щие процессы общественно-политической жизни Испании.

Рассуждения главы государства накануне Рождества выстроены в соответствии с риторическими традициями и прежде всего опираются на систему доводов к очевидным фактам, к эмоциональной и коллективной памяти нации. В рассматриваемых текстах фактуальная информация сведена к минимуму, поэтому практически отсутствуют естественные и логические доказательства $[19,20]$. Филипп VI в первую очередь апеллирует к эмоциональной и коллективной памяти нации, призывает гордиться достижениями прошлого и с уверенностью смотреть в будущее:

Ahora debemos valorar con orgullo lo que somos... (2018).

Y podemos sentirnos muy orgullosos de los valores que inspiran a nuestros ciudadanos... (2019).

Tenemos un gran potencial como pais (2019).

В рождественских обращениях Филиппа подача информации всегда сопряжена с апелляцией к личным и национальным чувствам, сформированным на основе коллективной памяти (особенно в период социально-экономического и политического кризиса). С самого начала своего правления монарх подчеркивает, что современная Испания - результат совместных усилий и усердной работы многих поколений:

[...] no debemos olvidar lo que hemos conseguido juntos con grandes esfuerzos y sacrificios, generación tras generación... (2014).

[...] lo que hemos construido juntos, lo que juntos hemos avanzado (2019).

Филипп старается выстроить доверительные отношения со своими подданными, поэтому чаще всего употребляет глаголы в первом лице множественного числа в изъявительном или повелительном наклонении, что подчеркивает его вовлеченность в общее дело (no vivimos tiempos fáciles, podemos sentirnos muy orgullosos, confiemos en nosotros mismos, pensemos en grande, avancemos con ambición).

Оптатив как обязательный рамочный элемент реализуется в максимально нейтральной фразе (поздравление с Рождеством). Примечательно, что Филипп (в отличие от своего предшественника короля Хуана Карлоса I) в конце каждого послания поздравляет своих подданных на четырех официальных языках (испанском, каталанском, галисийском и баскском), тем самым желая подчеркнуть значимость и уникальность каждого региона (идея единства в многообразии).

В роли врага выступают исключительно социально-экономические проблемы (безработица, коррупция, гендерное неравенство), а в роли союзника - страны ЕС и Латинской Америки, с которыми Испания разделяет единые ценности и идеалы: 
Somos una parte esencial de una Unión Europea... (2017).

Una sociedad... que es y se siente profundamente europea e iberoamericana ... (2019).

Институциональный (государственный) статус монарха обязывает его к демонстрации политической и идеологической нейтральности, уважения прав и свобод каждого члена общества:

Nadie en la España de hoy es adversario de nadie (2014)

[...] en la España constitucional caben todos los sentimientos y sensibilidades, caben las distintas formas de sentirse español... (2015).

Оценка итогов уходящего года имеет сдержанный характер и осуществляется в основном с помощью следующих номинаций, свидетельствующих о тяжелом социально-экономическом состоянии испанского общества: tiempos de mucha incertidumbre, preocupación, inquietud, dificultades económicas. Несмотря на сложности, Филипп отмечает успехи и достижения страны, которыми следует гордиться. Положительные итоги передаются с помощью традиционного набора характеристик, выраженных прилагательными с положительной семантикой:

una España moderna, de profundas convicciones democráticas, diversa, abierta al mundo, solidaria, potente y con empuje (2014);

un país mejor, más creativo, más dinámico (2018);

un país moderno con prestaciones sociales $y$ servicios públicos esenciales como en educación y en sanidad (2019).

Центральными в рождественских речах являются образ адресата (общества) и образ страны. Филипп создает положительный образ сплоченной и трудолюбивой нации, отмечает стойкость, мужество и самоотверженность простых граждан:

[...] tenemos capacidad y coraje de sobra... (2014);

[...] he visto... trabajo duro, honesto, sacrificado; mucha capacidad y talento... (2015).

В текстах обращений последовательно создается образ сильной и развитой в экономическом и социальном плане страны (una España moderna, de profundas convicciones democráticas, diversa, abierta al mundo, solidaria, potente y con етрије), ставшей важным политическим игроком на международной арене и примером для подражания (una nación respetada y apreciada en el mundo y con una profunda vocación universal). Испания предстает как стабильное правовое процветающее государство (Estado de Derecho, Estado de Bienestar), в котором смена власти осуществляется в соответствии с демократическими принципами правления, закрепленными Конституцией. Кроме того, постоянно упоминается идея единства в многообразии, что является еще одним поводом для гордости:
Y lo que hace de España una nación con una fuerza única, es la suma de nuestras diferencias que debemos comprender y respetar y que siempre nos deben acercar y nunca distanciar (2014);

[...] nuestras diferencias dentro del respeto a nuestra Constitución que reconoce la diversidad territorial que nos define y preserva la unidad que nos da fuerza (2019).

Необходимо принимать во внимание еще одну функцию монарха как верховного главы нации, стоящего над партийной борьбой, - его нравственное воздействие на общество. В данном случае король выступает как гомилет, опирающийся на понятные всем нравственные и этические ценностные доминанты (взаимопомощь, взаимопонимание, согласие, милосердие, толерантность, трудолюбие, верность, уважение, любовь к ближнему и пр.) и уделяющий особое внимание институту семьи, которая выступает символом стабильности (особенно в годы экономического кризиса) и продолжает играть чрезвычайно важную роль в современном испанском обществе:

He comprobado, una vez más, el valor que tiene en nuestra sociedad la familia... (2016);

[...] quiero destacar en primer lugar el deseo de concordia... (2019).

От общих характеристик рождественского послания как примера публичного выступления перейдем к анализу ключевых стратегий и тактик речевой манипуляции (по классификации О. Н. Паршиной).

\section{Стратегии и тактики речевой манипуляции} в рождественских посланиях Филиппа VI

В рождественских обращениях Филиппа стратегия самопрезентации подразумевает создание собственного имиджа и реализуется посредством (a) тактики отождествления (подчеркивание принадлежности к обществу с помощью местоимения «мы» с размытым содержанием) и (б) тактики солидаризачии (желание произвести впечатление общности ценностей и убеждений с помощью отсылки к общим моральным ценностям):

(a) [...] no vivimos tiempos fáciles... (2019);

(б) [...] mantengámonos unidos en los valores democráticos que compartimos para resolver nuestros problemas... (2019).

Идея ответственности власти за свои деяния впервые прослеживается в рождественской речи Филиппа VI от 2014 года, который уделяет особое внимание этому вопросу, тем самым создавая себе благоприятный имидж отца нации:

[...] la gran mayoría de servidores públicos desempeñan sus tareas con honradez y con voluntad de servir a los intereses generales...

La honestidad de los servidores públicos es un 
pilar básico de nuestra convivencia en una España que todos queremos sana, limpia.

Информационно-интерпретационная стратегия реализуется с помощью (а) тактики признания существования проблемы, (б) тактики акиентирования положительной информащии и (в) тактики указания пути решения проблемы. Филипп подчеркивает, что еще предстоит многое сделать, однако не стоит забывать о достижениях прошлого, благодаря которым возможно продвигаться вперед, а прогресс общества и страны в целом зависит от усилий каждого члена общества:

(a) Los desafíos que tenemos por delante no son sencillos... (2019);

(б) [...] hemos conseguido hacer realidad un pais nuevo y moderno, un país entre los más avanzados del mundo... (2017);

(8) Sin duda queda mucho por hacer, por mejorar y renovar. Para ello es preciso tener una conciencia clara y objetiva de nuestras fortalezas y de nuestras debilidades; $y$, además, tener una visión lo más realista y completa de cómo y hacia dónde va el mundo (2019).

Стратегия формирования эмоционального настроя адресата реализуется с помощью (a) тактики единения (единение граждан как «одного народа», стремление к общности взглядов), (б) тактики обращения к эмоциям адресата (например, апелляция к чувствам национальной гордости) и (в) тактики учета ценностных ориентиров адресата (отсылка к общим ценностям):

(a) Confiemos en España y mantengámonos unidos en los valores democráticos... (2019);

(6) Porque la historia de la España [...] es la historia de un gran triunfo de todos los españoles (2017);

(8) [...] es imprescindible que aseguremos en todo momento nuestra convivencia (2018).

Аргументативная стратегия в рождественских речах испанского монарха выражается с помощью тактики указания на перспективу (прогнозирование развития событий, выражение стратегических целей, позиций и намерений оратора), которая заключается в создании положительного образа будущего и реализуется через традиционный призыв с надеждой смотреть в будущее:

Si seguimos por ese camino, si lo hacemos así, y con todas nuestras energías, yo estoy convencido de que el año que viene -y los que vendrán despuésserán mucho mejores (2017).

Los desafios que tenemos por delante no son sencillos... pero estoy convencido de que los superaremos (2019).

Агитационная стратегия реализуется с помощью тактики призыва. Монарх призывает всех граждан объединиться и совместно работать ради всеобщего блага:

2018 nos espera en unos días y debemos seguir construyendo nuestro país... (2017).

Porque todos podemos hacer mucho por el bien común... (2018).

Таким образом, рождественские послания Филиппа VI можно рассматривать как ритуальный жанр институционального дискурса. В них отсутствуют стратегии дискредитации и нападения (тактика обвинения и оскорбления) и стратегия caмозащиты (тактика оправдания, тактика оспаривания, тактика критики), что связано с аполитичностью фигуры монарха.

\section{Заключение}

В политическом дискурсе оратор старается создать себе благоприятный имидж и повлиять на мысли и эмоции реципиента с помощью различных приемов и средств речевого воздействия, так как зачастую не может привести логические доводы и опереться на неоспоримые аргументы для подтверждения своей позиции. В результате анализа шести рождественских обращений Филиппа VI с 2014 по 2019 г. было выявлено, что они полностью соответствуют требованиям торжественного публичного выступления как особого коммуникативного события и характеризуются традиционным набором образов, транслируемых ценностей (общечеловеческие и демократические ценности) и стратегий речевого воздействия (стратегия самопрезентаиии, информационно-интерпретационная стратегия, стратегия формирования эмочионального настроя адресата, аргументативная стратегия, агитационная стратегия), обеспечивающих ритуальный акт институциональной коммуникации и подчеркивающих роль монарха как отца нации и гаранта коллективной идентичности.

\section{Список литературы}

1. Копнина Г. А. Речевое манипулирование. М.: Флинта, 2018. 176 с.

2. Баукин А. В. Манипулирование сознанием - явление современной действительности // Преподаватель XXI век. 2007. № 1. С. 148-152.

3. Стернин И. А. Введение в речевое воздействие. Воронеж, 2001. 252 с.

4. Ильичева Ю. А. Речевое манипулирование в политическом тексте // Вестник Санкт-Петербургского ун-та. Язык и литература. 2013. № 4. C. 172-184.

5. Кучеренко К. В. Манипулятивное воздействие в испанском политическом дискурсе: слова-стереотипы, слова-символы и слова-слоганы // Вестник МГИМО-Университета. 2012. № 5. С. 255-259. 
6. Помырляну Н. А. Речевое воздействие: способы, типы и приемы // Известия Южного федерального ун-та. Филол. науки. 2013. № 3. C. $71-78$.

7. Михалева О. Л. Политический дискурс. Специфика манипулятивного воздействия. М.: Либроком, 2009. 256 с.

8. Паршина О. Н. Стратегии и тактики речевого поведения современной политической элиты России. Астрахань: АГТУ, 2004. 195 с.

9. Абрамова Е. К., Агаркова О. А. Новогодние обращения Эммануэля Макрона: особенности композиции и содержания // Мир науки, культуры, образования. 2019. № 3 (76). С. 351-353.

10. Гаврилова М. В. Лингвистический анализ выступлений главы государства: тематика, направления и методы исследования // Политическая наука. 2017. № 2. С. 54-72.

11. Кондратенко Н. В. Новогоднее обращение как ритуальный жанр политического дискурса: макроструктурные компоненты и средства их выражения // Компьютерная лингвистика и интеллектуальные технологии: труды Междунар. конф. «Диалог 2007». М.: РГГУ, 2007. C. 302-306.

12. Ласица Л. А. Новогоднее обращение главы государства: семантические особенности ритуального жанра политического дискурса // Вестник Оренбургского гос. ун-та. 2017. № 1 (201). С. 19-24.

13. Ослопова В. Ю. Новогоднее обращение главы государства к народу как жанр политического дискурса // Вестник Томского гос. ун-та. 2009. № 329. C. 19-22.

14. Сладкевич Ж. Р. Организация семиотического пространства новогоднего поздравления президента (на материале новогодних обращений президентов России, Беларуси и Польши за 2000-2005 гг.) // Политическая наука. 2016. № 3. С. 168-193.

15. Фадеева Г. М. Рождественское телеобращение главы государства как медиасобытие // Вестник Московского гос. лингвист. ун-та. Языкознание. 2016. Вып. 7 (746). С. 273-285.

16. Medina López J. Discurso institucional e imagen en los mensajes de Navidad del rey de España (1975-2013) // Pragmática Sociocultural. 2016. № 4 (1). P. 25-73.

17. Ventero Velasco M. Los mensajes de Navidad del Rey. Madrid: La Ley, 2010. 440 p.

18. Лукьянова С. В. К вопросу о типологии дискурса // Вестник Псковского гос. ун-та. 2016. № 3. С. 150-154.

19. Хазагеров Г. Г. Политическая риторика. М.: Никколо-Медиа, 2002. 320 с.

20. Чудинов А. П. Очерки по современной политической метафорологии. Екатеринбург: УрГПУ, 2013. 176 с.

Селиванова Ирина Владимировна, аспирант, Московский государственный университет имени М. В. Ломоносова (ул. Ленинские горы, 1, Москва, Россия, 119991). E-mail: selivanova-irina@inbox.ru

Материал поступил в редакичюю 31.12.2019.

\section{DOI 10.23951/1609-624X-2020-2-61-67}

\section{FELIPE VI'S CHRISTMAS MESSAGES: A PRAGMATIC ASPECT}

\section{V. Selivanova}

Lomonosov Moscow State University, Moscow, Russian Federation

Introduction. The article deals with the communicative strategies and tactics of linguistic manipulation used in the six Christmas messages issued by the Spanish King Felipe VI from 2014 to 2019.

Material and methods. The analysis of Felipe VI's Christmas messages, published on the official website of the Royal House, was based on general scientific methods (description, observation, generalization, and systematization) as well as linguistic analysis methods (linguistic interpretation, content analysis, discursive analysis).

Results and discussion. This article describes some features of Felipe VI's Christmas messages (from 2014 to 2019), taking into account the current political situation of Spain. These texts are considered a ritual genre of institutional discourse and are analyzed in the context of political rhetoric. The paper is aimed to highlight how the messages are used with an ideological purpose to strengthen the image of the monarchy and to convince people of the necessity for peaceful coexistence, respect for the law, and national pride. The article also focuses on the images of the past, the present, the addressee (Spanish society) and the country. The scientific value of this paper is in describing the most popular communicative strategies and tactics of linguistic manipulation used by the Spanish King.

Conclusion. The monarch's Christmas messages can be considered a typical example of ceremonial eloquence in which the Head of State acts as a significant public figure, not only interpreting facts and events in order to preserve the unity of the nation and stability of the country, but also discussing moral issues based on universal values. It was revealed that Felipe VI tends to use a set of communicative strategies and tactics in order to underline the importance of peaceful coexistence in Spain and to emphasize his role as the only guarantor of stability, unity, prosperity and social justice.

Keywords: Christmas message, Spanish monarch, Felipe VI, ritual genre, political discourse. 


\section{References}

1. Kopnina G. A. Rechevoye manipulirovaniye [Linguistic manipulation]. Moscow, Flinta Publ., 2018. 176 p. (in Russian).

2. Baukin A. V. Manipulirovaniye soznaniyem - yavleniye sovremennoy deystvitel'nosti [Public opinion manipulation as a phenomenon of modern reality]. Prepodavatel'XXI vek, 2007, no. 1, pp. 148-152 (in Russian).

3. Sternin I. A. Vvedeniye $v$ rechevoye vozdeystviye [Introduction to linguistic manipulation]. Voronezh, 2001. 252 p. (in Russian).

4. Il'icheva Yu. A. Rechevoye manipulirovaniye v politicheskom tekste [Linguistic manipulation in political texts]. Vestnik Sankt-Peterburgskogo universiteta. Yazyk i literatura - Vestnik of Saint Petersburg University. Language and Literature, 2013, no. 4, pp. 172-184 (in Russian).

5. Kucherenko K. V. Manipulyativnoye vozdeystviye v ispanskom politicheskom diskurse: slova-stereotipy, slova-simvoly i slova-slogany [Manipulative influence in the Spanish political discourse: words stereotypes, words symbols and words slogans]. Vestnik MGMIMO-Universiteta-MGIMO Review of International Relations, 2012, no. 5, pp. 255-259 (in Russian).

6. Pomyrlyanu N. A. Rechevoye vozdeystviye: sposoby, tipy i priemy [Linguistic manipulation: methods, types and means]. Izvestiya Yuzhnogo federal'nogo universiteta. Filologicheskiye nauki - Proceedings of Southern Federal University. Philology, 2013, no. 3, pp. 71-78 (in Russian).

7. Mikhaleva O. L. Politicheskiy diskurs. Spetsifika manipulyativnogo vozdeystviya [Political discourse. Linguistic manipulation]. Moscow, Librokom Publ., 2009. 256 p. (in Russian).

8. Parshina O. N. Strategii i taktiki rechevogo povedeniya sovremennoy politicheskoy elity Rossii [Strategies and tactics of linguistic manipulation of the modern Russian political elite]. Astrakhan, ASTU Publ., 2004. 195 p. (in Russian).

9. Abramova E. K., Agarkova O. A. Novogodniye obrashcheniya Emmanuelya Makrona: osobennosti kompozitsii i soderzhaniya [Emmanuel Macron's New Year speeches: the features of composition and its contents]. Mir nauki, kul'tury, obrazovaniya - World of Science, Culture, Education, 2019, no. 3 (76), pp. 351-353 (in Russian).

10. Gavrilova M. V. Lingvisticheskiy analiz vystupleniy glavy gosudarstva: tematika, napravleniya i metody issledovaniya [Linguistic analysis of Head of State speeches: the theme, direction and methods of research]. Politicheskaya nauka - Political Science, 2017, no. 2, pp. 54-72 (in Russian).

11. Kondratenko N. V. Novogodneye obrashcheniye kak ritual'nyy zhanr politicheskogo diskursa: makrostrukturnye komponenty i sredstva ikh vyrazheniya [New Year's message as a ritual genre of political discourse: macrostructural components and means of expression]. Komp'yuternaya lingvistika i intellektual'nye tekhnologii: trudy Mezhdunarodnoy konferentsii "Dialog 2007" [Computational Linguistics and Intellectual Technologies: proceedings of the international conference "Dialogue 2007"]. Moscow, RSUH Publ., 2007, pp. 302-306 (in Russian).

12. Lasitsa L. A. Novogodneye obrashcheniye glavy gosudarstva: semanticheskiye osobennosti ritual'nogo zhanra politicheskogo diskursa [New Year's message of the Head of State: semantic features of the ritual genre of political discourse]. Vestnik Orenburgskogo gos. un-ta - Vestnik of Orenburg State University, 2017, no. 1 (201), pp. 19-24 (in Russian).

13. Oslopova V. Yu. Novogodneye obrashcheniye glavy gosudarstva k narodu kak zhanr politicheskogo diskursa [New Year's message of the Head of State as a genre of political discourse]. Vestnik Tomskogo gos. un-ta - Tomsk State University Journal, 2009, no. 329, pp. 19-22 (in Russian).

14. Sladkevich Zh. R. Organizatsiya semioticheskogo prostranstva novogodnego pozdravleniya prezidenta (na materiale novogodnikh obrashcheniy prezidentov Rossii, Belarusi i Pol'shi za 2000-2005 gg.) [The organization of the semiotic space of the New Year's president's greetings (based on the New Year messages of the presidents of Russia, Belarus and Poland in 2000-2015)]. Politicheskaya nauka - Political Science, 2016, no. 3, pp. 168-193 (in Russian).

15. Fadeyeva G. M. Rozhdestvenskoye teleobrashcheniye glavy gosudarstva kak mediasobytiye [Head of State Christmas address as a media event]. Vestnik Moskovskogo gosudarstvennogo lingvisticheskogo universiteta - Bulletin of Moscow State Linguistic University. Linguistics, 2016, no. 7 (746), pp. 273-285 (in Russian).

16. Medina López J. Discurso institucional e imagen en los mensajes de Navidad del rey de España (1975-2013). Pragmática Sociocultural, 2016, no. 4 (1), pp. 25-73.

17. Ventero Velasco M. Los mensajes de Navidad del Rey. Madrid, La Ley, 2010. 440 p.

18. Lukyanova S. V. K voprosu o tipologii diskursa [To the discourse typology]. Vestnik Pskovskogo gos. un-ta - Bulletin of the Pskov State University, 2016, no. 3, pp. 150-154 (in Russian).

19. Khazagerov G. G. Politicheskaya ritorika [Political rhetoric]. Moscow, Niccolo-Media Publ., 2002. 320 p. (in Russian).

20. Chudinov A. P. Ocherki po sovremennoy politicheskoy metaforologii [Essays on modern political metaphorology]. Yekaterinburg, Ural State Pedagogical University Publ., 2013. 176 p. (in Russian).

Selivanova I. V., Lomonosov Moscow State University (Leninskiye Gory, 1, Moscow, Russian Federation, 119991).

E-mail: selivanova-irina@inbox.ru 